\title{
Methylene blue removal using Eucalyptus Leaves: A Low Cost Protocol towards Environmental Sustainability
}

\author{
Soumen Dey, Priyanka Bhagat, Jhilirani Mohanta, and Banashree Dey
}

\section{ABSTRACT}

Indiscriminate use of dyes pollutes water bodies and poses a serious threat to mankind. Hence there is a need to address the problem. Eucalyptus leaves, being abundantly available were tested for the removal of methylene blue dye from water by both batch and column experiments. The material was characterized by Scanning electron microscopy, proximate analysis, and FTIR spectroscopy. SEM Images show a fractured surface with heterogeneous morphology. Batch experiments were conducted with respect to various physico-chemical parameters such as $\mathrm{pH}$, agitation speed, concentration, etc. The maximum adsorption capacity was found to be $66 \mathrm{mg} / \mathrm{g}$. Over a pH range of 4-8, high adsorption was seen. Adsorption follows a pseudo-secondorder kinetic model $\left(\mathbf{R}^{2}=\mathbf{0 . 9 9 9}\right)$. Regeneration was achieved with dilute hydrochloric acid and the material can be reused. Column studies show the possibility of field application. In a nutshell, a low-cost methodology was established with eucalyptus leaves for a safer environment.

Keywords: Methylene blue, Eucalyptus leaves, adsorption, regeneration.
Published Online: January 09, 2022 ISSN: $2684-4478$

DOI: $10.24018 /$ ejchem.2022.3.1.82

Soumen Dey*

Department of Chemistry, Central University of Jharkhand, Ranchi, India. (e-mail: soumen.dey@cuj.ac.in)

Priyanka Bhagat

Department of Chemistry, Central University of Jharkhand, Ranchi, India. (e-mail: priyabhagat4000@ gmail.com) Jhilirani Mohanta

Department of Chemistry, Central University of Jharkhand, Ranchi, India. (e-mail: mohanta.jhili@gmail.com)

Banashree Dey

Department of Chemistry, The Graduate School College for Women, Jamshedpur, India.

(e-mail: banashreeonline@ gmail.com)

*Corresponding Author

\section{INTRODUCTION}

In past few decades, a rapid increase in the number of textile and other dyes based industries have grown up. To add up, use of various dyes are increasing day by day. Dyes are used to color diverse products and large quantities of wastewater are discharge into streams and rivers which is a major source of water pollution. Azo dyes are non-biodegradable, highly toxic and proven carcinogens [1]. Dyes are mainly used in textile, paint, plastic industries; effluent from this industries are toxic in nature [2]-[4]. Dyes imposeserious threat to biological processes inside water bodies as the color of dyes prevent penetration of sunlight [5]-[6]. The presence of dyes in water bodies inhibits the growth of aquatic biota and decreases the oxygen solubility [7]. Wastewater containing dyes represents a threat to aquatic life so it's necessary to remove from wastewater [8].

But if methylene blue dose is higher than $0.09 \mathrm{~mL}$ per pound of body weight it cause dangerous side effects like chest pain, vomiting and confusion. Kidney and diabetics patient never takes it because it permanently destroyed the eyes. [9] Many methods are developed for removal of dyes in wastewater such as: coagulation and flocculation, sonochemical degradation, micellar enhanced ultrafiltration, cation exchange membranes, electrochemical degradation, membrane separation, oxidation and adsorption/precipitation [10]. Among all these, adsorption is easier and economically inexpensive process. In adsorption process adsorbents are used which are readily available and have very low cost. Activated carbon was used for the removal of color effluents in polluted wastewater [11]-[12]. Also different types of bio-adsorbents are reported from many years, such as carpobrotus edulis plant, sugarcane bagasse, agrobiomass, coconut husk, peat, straw, orange and uvaia seed. Recently neem leaf and orange peel powder has been reported. The adsorption of cationic dye on CTAB modified multi-component biosorbent is reported to be feasible [13]-[20].

Among all the purification process adsorption is easy, low cost, high efficiency, and recyclable process. An extensive variety of adsorbents like biomass, Zeolitic imidazolate frameworks-67 (ZIF-67), chitosan and its nanoparticles, carboxymethyl cellulose, acrylamide and graphene oxide, corn stalk polyethyleneimine-modified graphene oxide hydrogel, saw dust, clay based materials, rice husk, graphene, 
silica-sand/starch composite, magnetic porous organic Polymers, activated carbon, bio-char, graphitic magnetic nanocomposite, polyoxometalate@UiO-66, Fe@graphitecore-shell magnetic nanocomposite, porous diatomite microsphere, CMC-g-P(SPMA) superadsorbent hydrogel, bioconjugated graphene oxide hydrogel, reduced grapheme oxide, graphene oxide intercalated montmorillonite nanocomposite, cement kiln dust, aminated calcium lignosulfonate, palygorskite, manganese oxide, zinc oxide, $\mathrm{ZnO} / \mathrm{NiO}$ hollow microspheres, $\mathrm{ZnO}-\mathrm{Al}_{2} \mathrm{O}_{3}$ microspheres, $\mathrm{MeSrCuO}\left(\mathrm{Me}=\mathrm{Mg}\right.$ and $\mathrm{Ce}$ ) metal Oxides, $\mathrm{CeO}_{2}-\mathrm{Fe}_{2} \mathrm{O}_{3}-\mathrm{Al}_{2} \mathrm{O}_{3}$, $\mathrm{Ag} / \mathrm{ZnO} / 3 \mathrm{D}, \mathrm{CuMgAl}$ layered double hydroxide, binary oxides, polyaniline-alumina composite material, amberlite Ira-938 etc were tested [21]-[70]. With this line, we have demonstrated previously the application of various phytosorbents and chemisorbents for dye removal from contaminated water [71]-[82].

\section{MATERIALS AND METHODS}

\section{A. Biosorbent Preparation and Characterization}

Eucalyptus leaves are collected from the university campus and washed thoroughly to remove all the dirt. It was then refluxed with distilled water to completely remove any natural color present within, and dried it to $70{ }^{\circ} \mathrm{C}$ overnight. Dried leaves were crushed, sieved in different mesh sizes and used as such. Methylene blue is cationic dye. Molecular weight (MW) is $319.65 \mathrm{gmol}^{-1}$. Structure is given in Fig 1.<smiles></smiles>

Fig 1. Structure of methylene blue.

$100 \mathrm{mg} / \mathrm{L}$ stock solution was prepared by dissolving $0.05 \mathrm{gm}$ of MB in $500 \mathrm{~mL}$ distilled water. LR grade hydrochloric acid and sodium hydroxide was used to adjust solution $\mathrm{pH}$.

Analytical balance (Denver instrument corp.) was used for weighing of samples. Systronic digital $\mathrm{pH}$ meter 802 was used for $\mathrm{pH}$ measurements. Sohag orbital shaker incubator was used for shaking in the shaking range 100-150 rpm. Muffle furnace (Thermo-Scientific) was used for drying of samples. ZIESS SEM Analyzer was used for SEM study. Hitachi double beam spectrophotometer (model U-2900) equipped with UV solutions program NSJ was used for all UV measurements. Perkin Elmer (spectrum-II) and Remibench top centrifuge (R-8 M) were used for centrifugation.

The different concentration was measured using an UV-Visible spectrophotometer at a wavelength of $664 \mathrm{~nm}$. Calibration curve was obtained by using standard MB solution at $\mathrm{pH} 7$ and was fitted by a straight line with high coefficient value $\left(\mathrm{R}^{2}=0.987\right)$ as shown in Fig. 2.
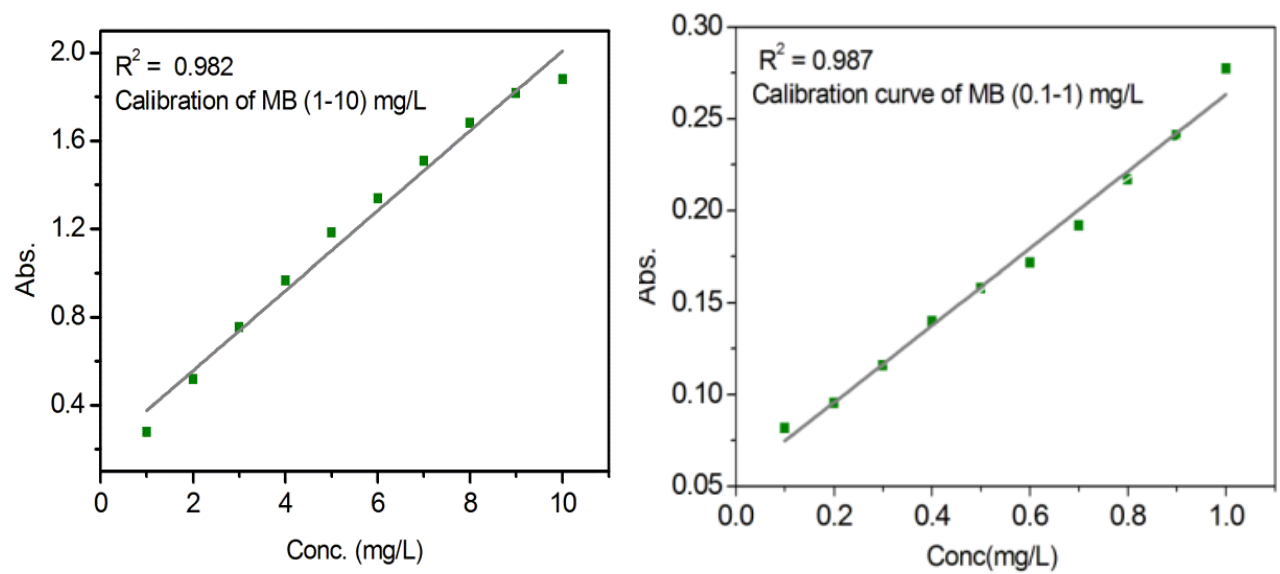

Fig. 2. Calibration curve of MB.

Batch studies were carried out by varying the initial dye concentration, contact time, agitation speed, adsorbent dose, particle size, $\mathrm{pH}$ and time. In this experiment $100 \mathrm{~mL}$ bottle was used in which appropriate amount of adsorbent is used in $50 \mathrm{~mL}$ dye solution with a known concentration. After equilibriation is reached, bottles were withdrawn from the shaker, centrifuged and absorbance was measured using UVvisible spectrophotometer. Concentration of dye was calculated using above calibration curves. The amount of dye adsorbed and the percentage removal was calculated using equation (1) and (2). 


$$
\begin{aligned}
& \mathrm{q}_{\mathrm{t}}=\frac{\mathrm{c}_{\mathrm{e}}-\mathrm{c}_{\mathrm{i}}}{\mathrm{m}} \times \frac{\mathrm{v}}{1000} \\
& \mathrm{R} \%=\frac{\mathrm{c}_{\mathrm{e}}-\mathrm{c}_{\mathrm{i}}}{\mathrm{c}_{\mathrm{e}}} \times 100
\end{aligned}
$$

where $\mathrm{q}_{\mathrm{t}}(\mathrm{mg} / \mathrm{gm})$ is the amount of dye adsorbed at equilibrium, $\mathrm{C}_{\mathrm{e}}(\mathrm{mg} / \mathrm{L})$ is the initial and $\mathrm{C}_{\mathrm{i}}$ is concentration of dye after shaking at any time $(\mathrm{min}) . \mathrm{V}$ is the volume $(\mathrm{mL})$ of dye, $\mathrm{m}(\mathrm{g})$ is the mass of adsorbent. $\mathrm{R} \%$ is the percentage of dye removal.

\section{RESULTS AND DISCUSSION}

Proximate Analysis was done for determination of ash, moisture, fixed carbon and volatile matter contents. It was carried out on eucalyptus leaves with $0.05 \mu \mathrm{m}$ mesh size.

\begin{tabular}{ccc}
\multicolumn{3}{c}{ TABLE I. PROXIMATE ANALYSES OF THE SAMPLES } \\
\hline S1. No & Parameter & Content $(\%)$ \\
\hline 1. & Moisture content & 9.8 \\
2. & Ash content & 73.10 \\
3. & Volatile content & 2.21 \\
4. & Fixed carbon content & 14.89 \\
\hline
\end{tabular}

\section{A. FT-IR Analysis}

This technique is used for the prediction of functional groups present in the sample. In this experiment FT-IR shows the difference before adsorption and when adsorption takes place. The FTIR analysis indicated broad band at $3467 \mathrm{~cm}^{-1}$, representing bonded O-H groups which gets shifted to $3363 \mathrm{~cm}^{-1}$ after adsorption (Fig. 3). The shift is attributed by interaction of dye with eucalyptus leaves.
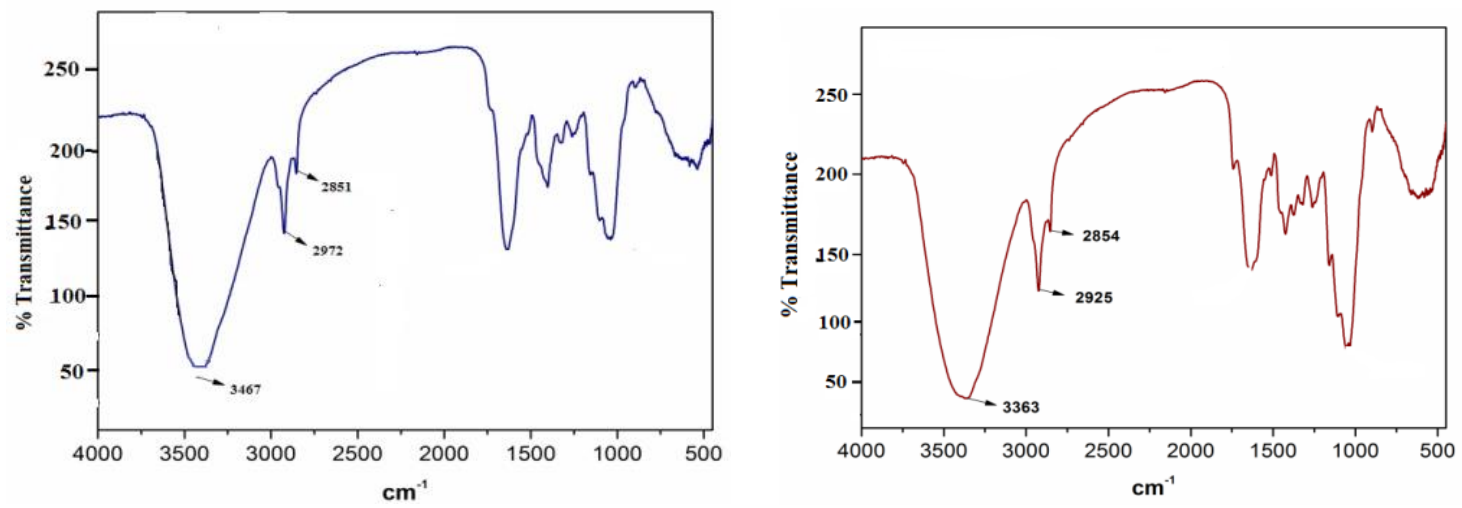

Fig. 3. FT-IR image of Eucalyptus leaves before and after adsorption of MB.

\section{B. SEM Analysis}

Scanning electron microscopy helps in determining the nature of the surface. Fig.4 (a) and (b) show the SEM images of prepared eucalyptus leaves and adsorption with MB solution. It was observed that pore size reduces after adsorption. This indicates that EU is effective in adsorbing methylene blue. Fig 4 represents SEM images of EU before and after adsorption.
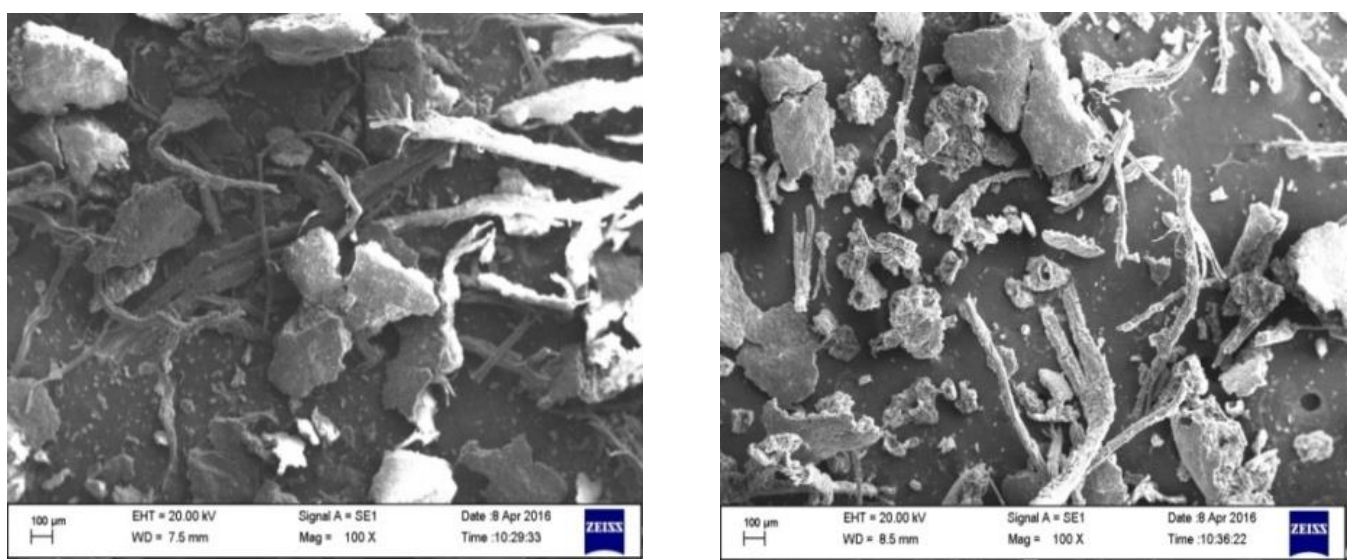

Fig. 4. SEM image of EU before (left) and after (right) adsorption of MB 


\section{Effect of Contact Time}

The effect of contact time on the adsorption of MB onto EU ranges from 10 to $60 \mathrm{~min}$. $5 \mathrm{mg} / \mathrm{L} \mathrm{MB}$ solution was prepared by diluting $100 \mathrm{mg} / \mathrm{L}$ stock solution. $0.1 \mathrm{~g}$ EU was taken and kept in shaker at room temperature in different time interval. Fig. 5 shows percentage removal of MB dye versus time. It was seen that the $88 \%$ adsorption occur in $10 \mathrm{~min}$, after that there is no sharp increase in adsorption (Fig. 5). This suggests that equilibrium sets at $10 \mathrm{~min}$.

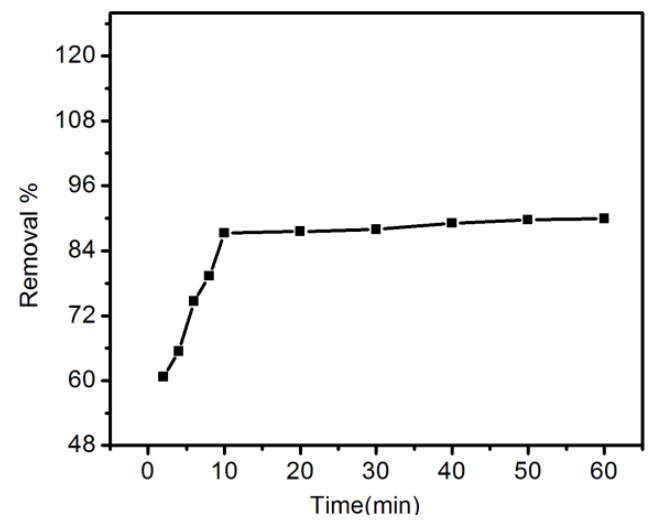

Fig. 5. Effect of contact time on MB adsorption.

\section{Effect of Initial Dye Concentration}

To demonstrate the effect of initial concentration, 5-30 mg/L concentration was taken. 0.1gm EU was added in different MB solution and shakes for 10min. Fig 6 shows the percentage removal vs concentration. There is a decrease in adsorption efficiency with increases of dye concentration. It was observed that at 'lower concentration there are sufficiently available active sites, due to this adsorption is fast. This is might be due to increase the competition for active site and adsorption process will decreases slowly.

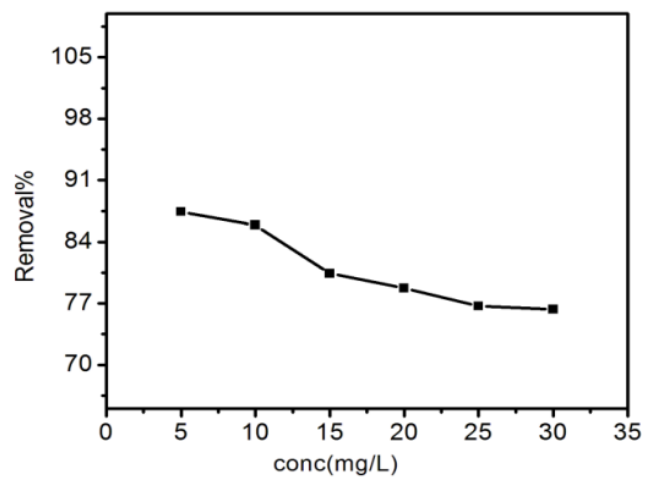

Fig. 6. Effect of initial dye concentration.

\section{E. Effect of Agitation Speed}

To evaluate the effect of agitation speed, $5 \mathrm{mg} / \mathrm{L}$ dye solution was taken in four bottles. The speed was ranges from 80 to $140 \mathrm{rpm}$ and shaken it for equilibrium time one by one. Fig. 7 shows the effect of agitation speed. It was observed that increase in agitation speed decreases the adsorption insignificantly. This may be due to slight occurrence of desorption.

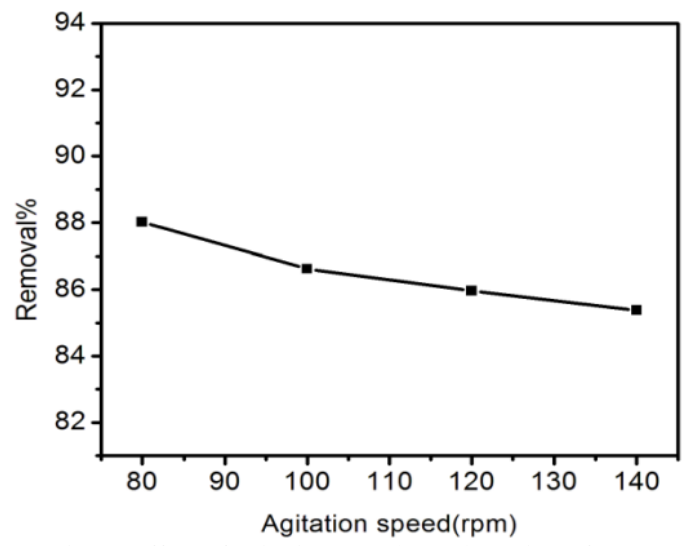

Fig. 7. Effect of agitation speed on adsorption of MB. 


\section{F. Effect of Adsorbent Dose}

Fig. 8 shows the effect of adsorbent dose which was carried out by using different amount of EU (0.05 to $0.25 \mathrm{~g}$ ), added to fixed initial dye concentration of MB. Initially concentration increases rapidly with increase in dose. This is due to availability of greater surface area. But after certain dosage efficiency becomes constant. This is due to fast superficial adsorption onto the adsorbent surface. Thus when adsorbent doses increases, amount of dye adsorbed per unit mass decreases.

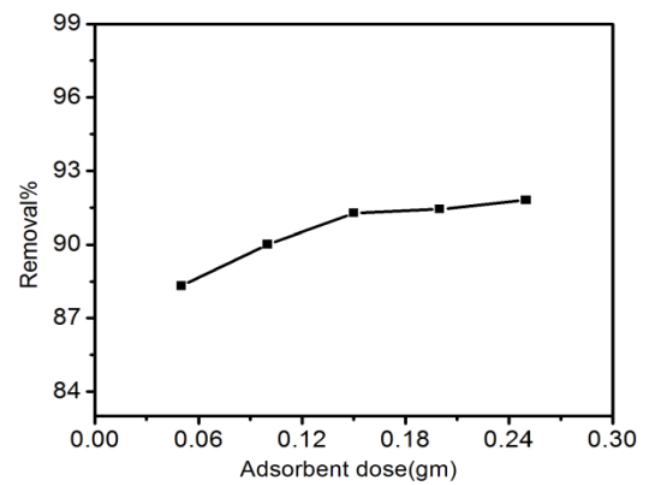

Fig. 8. Effect of adsorbent dose on adsorption of MB onto EU.

\section{G. Effect of Particle Size}

Fig. 9 shows the adsorption of MB of different particle sizes. Here initial dye concentration was taken and agitated for equilibrium time. It was observed that there is slow decrease in adsorption removal with increase in mesh size. Size is inversely proportional to surface area. Larger the size, lower was the adsorption. Hence small size was used which leads to greater adsorption.

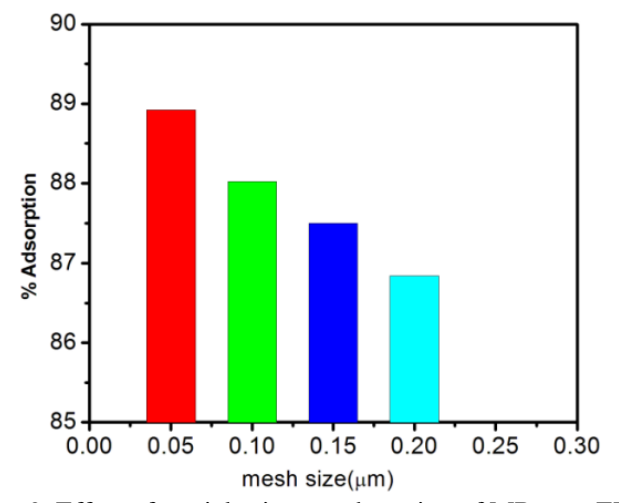

Fig. 9. Effect of particle size on adsorption of MB onto EU.

\section{H. Effect of $p H$}

The effect of $\mathrm{pH}$ was shown in Fig. 10. pH of initial dye solution is adjusted by adding small amount of $0.1 \mathrm{M} \mathrm{NaOH}$ or $\mathrm{HCl}$. Adsorption capacity increases with increasing $\mathrm{pH}$. EU has larger number of active sites. In $\mathrm{pH} 2$ there is large number of $\mathrm{H}^{+}$ions present which compete with active sites of $\mathrm{EU}$ for $\mathrm{MB}$ adsorption. When $\mathrm{pH}$ is gradually increased, number of $\mathrm{H}^{+}$ion deceases and electrostatic interaction between $\mathrm{MB}$ and EU gets better and efficiency increases. Fig. 10 represents the effect of $\mathrm{pH}$ on adsorption of dye.

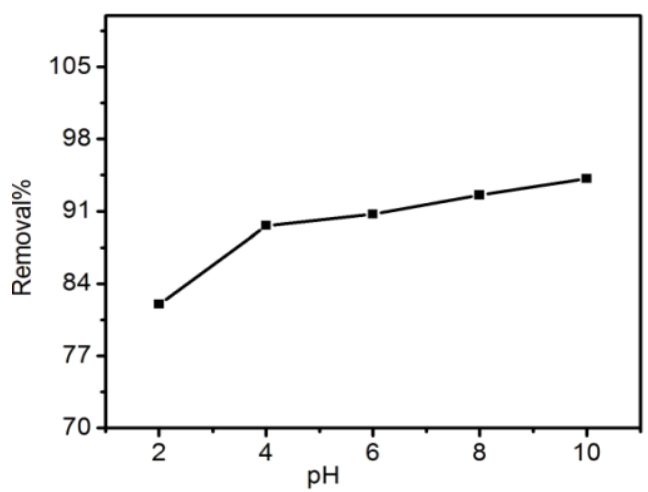

Fig. 10. Effect of $\mathrm{pH}$ on adsorption of $\mathrm{MB}$ onto EU. 


\section{Adsorption Kinetics}

For knowing the mechanism of dye adsorption and designing the adsorption system, kinetics is one of the important parameter. For this pseudo-first-order, pseudo-second-order and intra-particle diffusion models were evaluated to fit the kinetics experiments data.

1) Pseudo first order kinetics model

In 1898 Lagergren developed the pseudo-first-order kinetic model is shown in (3).

$$
\frac{d q_{t}}{d t}=k_{1}\left(q_{e}-q_{t}\right)
$$

where $q_{\mathrm{e}}$ and $q_{t}$ are the amounts of dyes adsorbed at equilibrium and at time $t(\mathrm{mg} / \mathrm{g})$, respectively, and $k_{1}$ is the pseudo-first-order rate constant $\left(\mathrm{min}^{-1}\right)$ The integrated form of (3) with the initial condition, $q_{t}=0$ at $t=$ 0 is shown in (4). The rate constant can be determined from linear plot of $\log \left(q_{e}-q_{t}\right)$ versus time.

$$
\log \left(q_{e}-q_{t}\right)=\log q_{e}-\frac{k_{1 t}}{2.303}
$$

\section{2) Pseudo second order kinetics model}

Linearized form of the Pseudo second-order kinetic model is shown in below (5):

$$
\frac{\mathrm{t}}{\mathrm{q}_{\mathrm{t}}}=\frac{1}{\mathrm{k}_{2}\left(\mathrm{q}_{\mathrm{e}}\right)^{2}}+\frac{\mathrm{t}}{\mathrm{q}_{\mathrm{e}}}
$$

where $K_{2}$ is the equilibrium rate constant of pseudo-second-order adsorption [g/(mg.min)]. A plot between $\mathrm{t} / \mathrm{q}_{\mathrm{t}}$ vs. $\mathrm{t}$ gives the value of rate constant $\mathrm{K}_{2}$ (g/mg.min).

3) Intra particle diffusion model

Weber-Morris developed the intra-particle diffusion model which is shown in (6):

$$
\mathrm{q}_{\mathrm{t}}=\mathrm{k}_{3} \mathrm{t}^{1 / 2}+\mathrm{c}
$$

where $\mathrm{k}_{3}$ is the inter particle diffusion rate constant $\left(\mathrm{mg} . \mathrm{g}^{-1} \mathrm{~min}^{0.5}\right)$ and $\mathrm{C}$ is intercept $\left(\mathrm{mg} . \mathrm{g}^{-1}\right)$, which is the thickness of boundary layer.

The kinetics of MB adsorption was analyzed with respect to pseudo-first order, pseudo-second order and intra-particle diffusion model. By using relevant equations all the graphs was plotted and shown below. The $1^{\text {st }}$ and $2^{\text {nd }}$ order rate constants were determined. The kinetic data of Pseudo $2^{\text {nd }}$ order model are fitted with highest correlation coefficient $\left(\mathrm{R}^{2}=0.999\right)$ which is better than pseudo-first $\left(\mathrm{R}^{2}=0.982\right)$ intra particle model $\left(R^{2}=0.933\right)$. These result shows that adsorption of MB onto EU might be best described by pseudo $2^{\text {nd }}$ order kinetic model. Fig. 11 shows all the kinetic models. From the observations, it seems that there is a combining effect of physi-sorption and chemi-sorption.
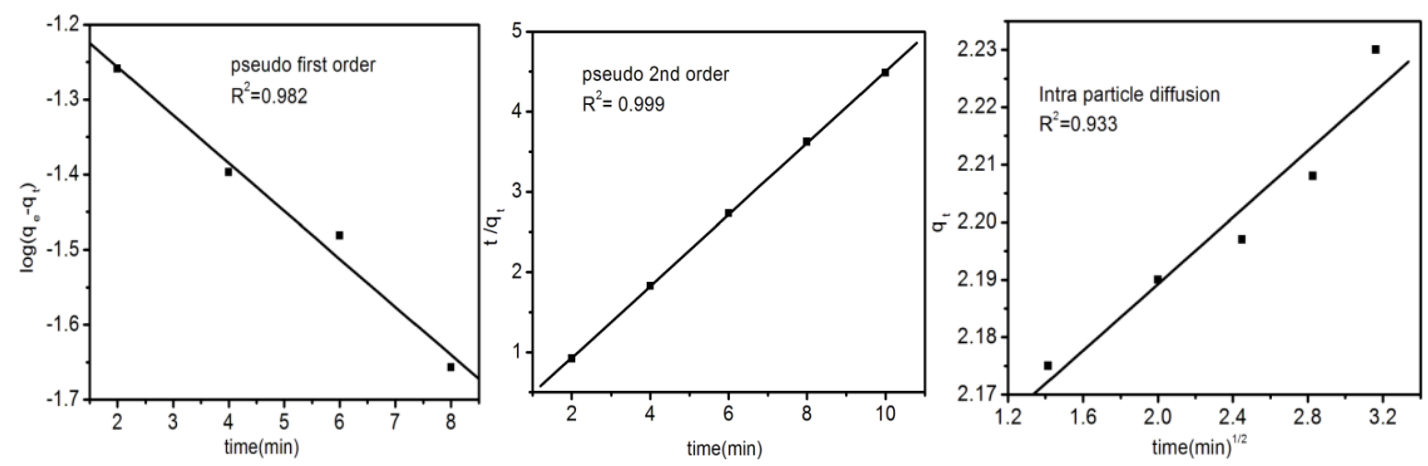

Fig. 11. Various kinetic models.

\section{COLUmn STUdy}

Only batch experiment may not be conducive whether a material will work on pilot scale. Column study was carried out to check whether EU can be used in industrial wastewater treatment. In this experiment adsorbent bed of knowing amount was prepared and $5 \mathrm{mg} / \mathrm{L}$ methylene blue solution was passed through dropwise. A constant flow rate is maintained. Fixed bed glass column was used and experiments were performed at $\mathrm{pH}$ 7. Results are summarized in Table 2. 
TABLE II. SELECTED COLUMN PARAMETERS

\begin{tabular}{cccccc}
\hline $\begin{array}{c}\text { Particle size of } \\
\text { adsorbent }(\mu \mathrm{m})\end{array}$ & $\begin{array}{c}\text { Amount of adsorbent } \\
(\mathrm{g})\end{array}$ & $\begin{array}{c}\text { Diameter of column } \\
(\mathrm{cm})\end{array}$ & $\begin{array}{c}\text { Height of adsorbent } \\
\text { bed }(\mathrm{cm})\end{array}$ & $\begin{array}{c}\text { Total amount of contaminant } \\
\text { passed }(\mathrm{mL})\end{array}$ & $\begin{array}{c}\text { Bed volume } \\
(\mathrm{mL})\end{array}$ \\
\hline 1.5 & 1 & 1.2 & 7.3 & 600 & 1400 \\
1 & 1 & 1.2 & 7.3 & 1400 & 169.69 \\
0.5 & 1 & 1.2 & 7.3 & 2300 & 282.9 \\
\hline
\end{tabular}

\section{REGENERATION AND REUSE}

Regeneration study helps to understand the mechanism of adsorption. The scope of recovery of adsorbate as well as adsorbent also called regeneration. If the adsorbent can be successfully regenerated, then it will make the treatment process more economically advantageous. To achieve that, $0.5 \mathrm{~g} \mathrm{MB}$ treated EU was taken in three $50 \mathrm{~mL}$ of conical flask. In these flasks, one acidic $(25 \mathrm{~mL}, 1 \mathrm{~N} \mathrm{HCl})$, one basic $(25 \mathrm{~mL}, 1 \mathrm{~N}$ $\mathrm{NaOH})$ and one neutral $(25 \mathrm{~mL}, 1 \mathrm{~N} \mathrm{NaCl})$ solution was taken and shaken for overnight. The final readings of concentration were noted down. A graph between percentage desorption and $0.1 \mathrm{~N}$ solution was plotted. In case of hydrochloric acid, the percentage desorption was very high. EU was then thoroughly washed with distilled water and adjusted to $\mathrm{pH} 7$. A continuous cycle experiments were conducted for three cycles. It was found that after each cycle efficiency is retained by almost 95\%. Fig. 12 shows desorption with $\mathrm{HCl}$ and $\mathrm{NaOH}$ solution. This is in accordance to our previous works where we have demonstrated highly efficient regeneration and reuse of various materials for diverse dye removal from contaminated water [71][82].

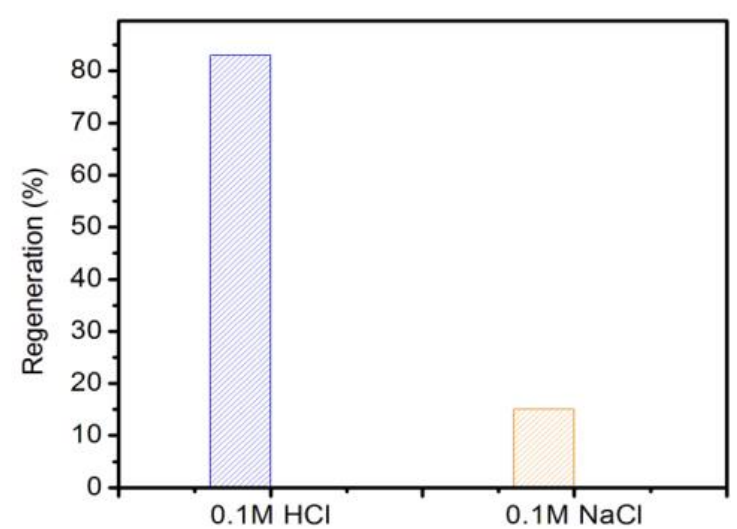

Fig. 12. desorption of dye loaded material in $0.1 \mathrm{~N} \mathrm{HCl}$ and $0.1 \mathrm{~N} \mathrm{NaCl}$.

\section{CONCLUSION}

Present study shows that Eucalyptus leaves, a cheap and easily available material, that can be effectively used to remove methylene blue from solution. Proximate analysis showed good carbon content which favors adsorption. Percentage carbon was found to be. The moisture content $(9.8 \%)$, volatile content $(2.21 \%)$ and ash content $(76.10 \%)$ were also found to be quite reasonable. FTIR spectra show little change in the surface properties of adsorbent after adsorption as compared to that of before adsorption. Scanning Electron micrographs exhibited that EU had a considerable number of pores where there is a good possibility of methylene blue dye to be trapped and adsorbed into these pores and also there is no significantly change in the surface topography of EU before and after adsorption of dye due to lack of dye and adsorbent ratio. Adsorption tends to increase with contact time. At first the increase in adsorption is very rapid as there are lots of free sites for the adsorption to take place. Rate of adsorption decreases at later stages till saturation is reached due to saturation of active sites. The optimum contact time for equilibrium was found to be ten minutes. The removal efficiency of adsorbent is maximum at higher $\mathrm{pH}$ range. As adsorbent dose increases, adsorption increases due to the availability of free sites. Concentration of adsorbent is taken as the optimum adsorbate dose. As we increase adsorbate dose more than the optimum, the subsequent increase in adsorption is very less and it becomes cost ineffective. There is decrease in adsorption with the increase in initial dye concentrations due to the high driving force for mass transfer at a high initial dye concentration. The adsorption process follows pseudo second order kinetics.

\section{CONFLICT OF INTEREST STATEMENT}

All the authors declare that there is no conflict of interest. 


\section{ACKNOWLEDGEMENT}

Authors thank Central University of Jharkhand for infrastructural facilities.

\section{REFERENCES}

[1] Saleh VM, Abudabbus M. Removal of Methylene Blue Dye Using Roselle Petals from Aqueous Solutions. Int J Chem Mol Nucli Mat and Metal Engg.2013;7:340-343.doi.org/10.5281/zenodo.133411.

[2] Afroze S, Sen TK, Ang HM. Adsorption performance of continuous fixed bed column for the removal of methylene blue (MB) dye using Eucalyptus sheathiana bark biomass. Res Chem Intermed.2016; 42:2343-2364. doi. 10.1007/s11164-015-2153-8.

[3] $\mathrm{Li} \mathrm{JW}, \mathrm{Li} \mathrm{J}$. Removal of methylene blue from aqueous solution by Adsorption onto crofton weed stalk. Bio Resources. 2013; 8:2521-2536. doi:10.15376/BIORES.8.2.2521-253.

[4] Kankılıç GB, Metin AU. Phragmites AustralisPhr as a new cellulose source: Extraction, characterizationand adsorption ofmethylene blue. JMol Liq. 2020; 312:113313-113323. doi.org/10.1016/j.molliq.2020.113313.

[5] Shooto ND, Nkutha CG, Guilande NR, Naidoo EB. Pristine and modified mucuna beans adsorptive studies of toxic lead ions and methylene blue dye from aqueous solution.South Afr J Chem Engg. 2020; 31:33-43. doi.org/10.1016/j.sajce.2019.12.001.

[6] Lopez-Vasquez A, Suarez A, Gomez C. Assessment of Dye Adsorption by Luffa Cylindrica fibers Using Experimental Design Methodology. Proceedings of the World Congress on Engineering WCE.pp. 3-8, vol I., London, U.K., 2012.

[7] Pathania V, Sharma S, Singh P. Removal of methylene blue by adsorption onto activated carbon developed from ficuscaricabast.Arb J Chem. 2017; 10:S1445-S1451.doi.org/10.1016/j.arabjc.2013.04.021

[8] Mane VS, Vijay Babu PV. Studies on the adsorption of Brilliant Green dye from aqueous solution onto low-cost $\mathrm{NaOH}$ treated saw dust. Desalination.2011; 273:321-329. doi. 10.1016/j.desal.2011.01.049.

[9] Murat O, Dietrich EL, Mohammed H, George AP. Cellular and Molecular Actions of Methylene Blue in the Nervous System. Medici Res Reviews.2010;31:93-117. doi: 10.1002/med.20177.

[10] Mesquita B, Botrel C, Magriotis ZM, Saczk AA, Coelho SM, Sales PF.Removal of methylene blue by orange and uvaia seeds. $J$ Adv Agri.2015; 3:236-251. doi: https://doi.org/10.4491/eer.2018.107.

[11] Khatod I. Removal of Methylene Blue Dye from Aqueous Solutions by Neem Leaf and Orange Peel Powder.Proceedings of the International Conference on Global Scenario in Environment and Energy, Int J Chem Tech Research, pp. 572-577, vol. 5, Bhopal, Madhya Pradesh, India, 2013.

[12] Oden MK, Celalettin O. Removal of Methylene Blue Dye from Aqueous Solution Using Natural Boron Ore and Leach Waste Material: Adsorption Optimization Criteria.Inter J Current Res Acad Review.2014; 1:66-71. ISSN: 2347-3215.

[13] Patil S, Das SR, Patel N. Removal of methylene blue, a basic dye from aqueous solutions by adsorption using teak tree (Tectonagrandis) bark powder. Int J Environ Sci. 2011; 1:711-726.ISSN: 0976 - 4402.

[14] Dabagh A, Bagui A, Abali M, Aziam R, ChibanM, SinanM, et al. Adsorption of Crystal Violet from aqueous solution onto ecofriendly native Carpobrotus edulis plant.Materials Today: Proceedings.

2021; 37(3):3980-3986. doi.org/10.1016/j.matpr.2020.10.349.

[15] Nandi BK, Goswami A, Purkait MK. Adsorption characteristics of brilliant green dye on kaolin. J Hazard Mater. 2009; 161:387395. doi. 10.1016/j.jhazmat.2008.03.110.

[16] Ayad MM, El-Nasr AA. Adsorption of Cationic Dye (Methylene Blue) from Water Using Polyaniline Nanotubes Base.J Phys Chem C.2010;114:14377-14383.doi.org/10.1021/jp103780w.

[17] Aruna, Bagotia N, Sharma AK, Kumar S. A review on modified sugarcane bagasse biosorbent for removal of dyes. Chemosphere. 2021;268:129309-129324.doi.org/10.1016/j.chemosphere.2020.129309.

[18] Gottipati R, Mishra S. Application of Biowaste (waste generated in biodiesel plant) as an adsorbent for the removal of hazardous dye-methylene blue from aqueous phase. Brazilian J Chem Eng. 2010;27:357-367. doi.10.1590/S0104-66322010000200014.

[19] Mishra S, Cheng L, Maiti A. The utilization of agro-biomass/byproducts for effective bio-removal of dyes from dyeing wastewater: A comprehensive review.J Environl Chem Engg. 2021; 9:104901-1049923. doi.org/10.1016/j.jece.2020.104901.

[20] Esan OS, Abiola ON, Owoyomi O, Christopher OA, Osundiya MO. Adsorption of Brilliant Green onto Luffa Cylindrical Sponge: Equilibrium, Kinetics, and Thermodynamic Studies. ISRN Phy Chem. 2014; 2014:1-12.doi.org/10.1155/2014/743532.

[21] Hosseinzadeh H, Ramin S. Fabrication of starch-graft-poly(acrylamide)/grapheneoxide/hydroxyapatite nanocomposite hydrogel adsorbent for removalof malachite green dye from aqueous solution. Inter J Bio Macromol. 2018; 106:101-115.doi: 10.1016/j.ijbiomac.2017.07.182.

[22] Qiu J, Feng Y, Zhang X, Jia M, Yao J. Acid-promoted synthesis of UiO-66 for highly selective adsorption of anionic dyes: Adsorption performance and mechanisms. J Colloid Inter Sci.2017;499:151-158.doi: 10.1016/j.jcis.2017.03.101.

[23] Bulut Y, Karaer H. Adsorption of methylene blue from aqueous solution by crosslinked chitosan/bentonite composite. J Disper Sci Tech.2015;36:61-67.doi.org/10.1080/01932691.2014.888004.

[24] Asfaram A, Ghaedi M, Yousefi F, Dastkhoon M. Experimental design and modeling of ultrasound assisted simultaneous adsorption of cationic dyes onto ZnS: Mn -NPs-AC from binary mixture.Ultrasonics Sonochemi. 2016; 33:77-89. doi.org/10.1016/j.ultsonch.2016.04.016.

[25] Yasemin B, Haluk A. A kinetics and thermodynamics study of methylene blue adsorption on wheat shells. Desalination. 2006; 194:259-267.doi.org/10.1016/j.desal.2005.10.032.

[26] Altaher H, Khalil TE, Abubeah R. The effect of dye chemical structure on adsorption on activated carbon: a comparative study. Color Tech. 2014; 130:205-214.doi.org/10.1111/cote.12086.

[27] Leite LS, Maselli BS, Umbuzeiro GA, Nogueira RFP. Monitoring ecotoxicity of disperse red 1 dye during photo-fenton degradation. Chemosphere. 2016; 148:511-517.doi.org/10.1016/j.chemosphere.2016.01.053.

[28] Al-Rashdi BAM, Johnson DJ, Hilal N. Removal of heavy metal ions by nanofiltration. Desalination. 2013;315:2-17. doi. 10.1016/j.desal.2012.05.022.

[29] Peterskova M, Valderrama C, Gibert O, Cortina JL. Extraction of valuable metal ions (Cs, Rb, Li, U)from reverse osmosis concentrate using selective sorbents. Desalination. 2012;286:316-323. doi. 10.1016/j.desal.2011.11.042.

[30] Lin Q, Gao M, Chang J, Ma H. Adsorption properties of crosslinking carboxymethyl cellulosegrafting dimethyldiallylammonium chloride for cationic and anionicdyes. Carbohydrate Polymers. 2016; 151:283-294.doi: 10.1016/j.carbpol.2016.05.064.doi: $10.3390 /$ molecules 25163624 .

[31] Khan MA, Siddique M, Wahid F, Khan R. Removal of reactive blue 19 dye by sono, photo and sonophotocatalytic oxidation using visible light. Ultrason Sonochem. 2015; 26:370-377. doi: 10.1016/j.ultsonch.2015.04.012.

[32] Ainscough TJ, Alagappan P, Oatley-Radcliffe DL, Barron AR. A hybrid super hydrophilic ceramic membrane and carbon nanotube adsorption process for clean water production and heavy metal removal and recovery in remote locations. J Water Process Eng. 2017; 19:220-230. doi.org/10.1016/j.jwpe.2017.08.006.

[33] Natarajan S, Bajaj HC, Tayade RJ. Recent advances based on the synergetic effect of adsorptio for removal of dyes from waste water using photocatalytic process. J Environ Sci.2017; 65:201-222.doi: 10.1016/j.jes.2017.03.011. 
[34] Fu J, Xin Q, Wu X, Chen Z, Yan Y, Liu S. Selective adsorption and separation of organic dyes from aqueous solution on polydopamine microspheres. J Colloid Inter Sci. 2016; 461:292-304. doi: 10.1016/j.jcis.2015.09.017.

[35] Javadian H.Application of kinetic, isotherm and thermodynamic models for the adsorption of $\operatorname{Co(II)~ions~on~}$ polyaniline/polypyrrole copolymer nanofibers from aqueous solution.J Ind Eng Chem. 2014; 20(6):4233-4241. doi: 10.1016/j.jiec.2014.01.026.

[36] Jitjaicham S, Kampalanonwat P, Supaphol P. Metaladsorption behavior of 2,4-dinitrophenyl hydrazinemodified polyacrylonitrile nanofibers. Express Polymer Letters. 2013; 7:832-841.doi. 10.3144/expresspolymlett.2014.

[37] Ren X, Xiao W, Zhang R, Shang Y, Han R. Adsorption of crystal violet from aqueous solution by chemically modified phoenix tree leaves in batch mode. Desalination Water Treat. 2015; 53:1324-1334.doi.10.1080/19443994.2013.859105.

[38] Du X, Wang C, Liu J, Zhao X, Zhong J, Li Y, et al. Extensive and selective adsorption of ZIF-67 towards organic dyes: Performance and mechanism, J Colloid Inter Sci.2017; 506:437-441.doi: 10.1016/j.jcis.2017.07.073.

[39] Shajahana A, Shankar S, Sathiyaseelan A, Narayan KS, Narayanan V, Kaviyarasan V, et al. Comparative studies of chitosan and its nanoparticles for theadsorption efficiency of various dyes. InternationalJ. Biol. Macromole.2017;104:14491458.doi.org/10.3390/nano10040748.

[40] Varaprasad K, Jayaramudu T, Sadiku ER. Removal of dye by carboxymethyl cellulose, acrylamide and graphene oxide via a free radical polymerization process.Carbohydrate Polymers. 2017; 164:186-194. doi.org/10.1016/j.carbpol.2017.01.094.

[41] Ma D, Zhu B, Cao B, Wang J, Zhang J. Fabrication of the novel hydrogel based on waste corn stalk for removal of methylene blue dye from aqueous solution. Appli Surface Sci. 2017; 422:944-952. doi: 10.1016/j.apsusc.2017.06.072.

[42] Wang X, Liu Q, Liu J, Chen R, Zhang H, Li R, et al. 3D self-assembly polyethyleneimine modified graphene oxide hydrogel for the extraction of uranium from aqueous solution. Appli Surf Sci. 2017; 426:1063-1074.doi.org/10.1016/j.scitotenv.2021.151258.

[43] Banerjee S, Chattopadhyaya V MC. dsorption characteristics for the removal of a toxic dye, tartrazine from aqueous solutions by a low cost agricultural by-product. Arab J Chem.2017;10:S1629-S1638.doi.org/10.1016/j.arabjc.2013.06.005.

[44] Ngulube T, Gumbo JR, Masindi V, Maity A. An update on synthetic dyes adsorption onto clay based minerals: A state-of-art review. J Environ Manage. 2017; 191:35-57. doi. 10.1016/j.jenvman.2016.12.031.

[45] Kausar A, Iqbal M, Javed A, Aftab K, Nazli JH, Bhatti HN, et al. Dyes adsorption using clay and modified clay: A review. $J$ Mole Liq.(2018) 256:395-407. doi. 10.1016/j.molliq.2018.02.034.

[46] Aguiar JE, Cecilia JA, Tavares PAS, Azevedo DCS, Castellon ER,Lucena SMP, et al. Adsorption study of reactive dyes onto porous clay heterostructures. Appli Clay Sci. 2017; 135:35-44. doi. 10.1016/j.clay.2016.09.001.

[47] Sawasdee S, Jankerd H, Watcharabundit P. Adsorption of dyestuff in house hold-scale dyeing onto rice husk. Energy Procedia. 2017; 138:1159-1164.doi:10.24294/ace.v1i2.624.

[48] Essawy NAE, Ali SM, Farag HA, Konsowa AH, Elnouby M, Hamad HA. Green synthesis of graphene from recycled PET bottle wastes for use in the adsorption of dyes in aqueous solution. Ecotox Environ Safety. 2017; 145:57-68. doi. 10.1016/j.ecoenv.2017.07.014.

[49] Li P, Gao B, Li A, Yang H. Highly selective adsorption of dyes and arsenate from their aqueous mixtures using a silicasand/cationized-starch composite Micropor andMesopor Mater.2018; 263:210-219. doi. 10.1016/j.micromeso.2017.12.025.

[50] Huang L, He M, Chen B, Cheng Q, Hu B. Facile Green Synthesis of Magnetic Porous Organic Polymers for Rapid Removal and Separation of Methylene Blue. ACS Sustainable Chem Eng. 2017; 5:4050-4055.doi.org/10.1021/acssuschemeng.7b00031.

[51] Goswami M, Phukan P. Enhanced adsorption of cationic dyes using sulfonic acid modified activated carbon. J Environ Chem Eng. 2017; 5(4):3508-3517. doi. 10.1016/j.jece.2017.07.016.

[52] Menya E, Olupot PW, Storz H, Lubwama M, Kiros Y. Production and performance of activated carbon from rice husks for removal of natural organic matter from water: A review. Chem Eng Res Design. 2018; 129:271-296. doi.10.1016/j.cherd.2017.11.008.

[53] Dawood S, Sen TK, Phan C. Adsorption removal of Methylene Blue (MB) dye from aqueous solution by bio-char prepared from Eucalyptus sheathiana bark: kinetic, equilibrium, mechanism, thermodynamic and process design. Desalinatio Water Treat.2016; 57(59):28964-28980.doi.org/10.1080/19443994.2016.1188732.

[54] Dai H, Peng X, Yang W, Hu F, Qiu Z, Zou Y. Synthesis and characterization of graphitic magnetic mesoporous nanocomposite and its application in dye adsorption. J Mole Liq.2018; 253:197-204. doi.10.1016/j.molliq.2018.01.030.

[55] Zeng L, Xiao L, Long Y, Shi X. Trichloroacetic acid-modulated synthesis of polyoxometalate@UiO-66 for selective adsorption of cationic dyes. J Collo Inter Sci.2018;516:274-283. doi. 10.1016/j.jcis.2018.01.070.

[56] Konickia W, Hełminiak A, Arabczyk W, Mijowsk E. Adsorption of cationic dyes onto Fe@graphitecore-shell magnetic nanocomposite: Equilibrium,kinetics and thermodynamics. Chem Eng Res Design. 2018; 129:259270.doi.org/10.1177/0263617418819164.

[57] Yan S, Huo W, Yang J, Zhang X, Wang Q, Wang L, et al. Green synthesis and influence of calcined temperature on the formation of novel porous diatomite microspheres for efficient adsorption of dyes. Powder Tech. 2018; 329:260-269. doi. 10.1007/s40145017-0253-1.

[58] Salama A. Preparation of CMC-g-P(SPMA) super adsorbent hydrogels: Exploring their capacity for MB removal from waste water. Inter J Bio Macromol. 2018; 106:940-946. doi. 10.1016/j.ijbiomac.2017.08.097.

[59] Soleimani K, Tehrani D, Adeli M. Bioconjugated graphene oxide hydrogel as an effective adsorbent for cationic dyes removal. Ecotox and Environ Safety. 2018; 147:34-42. doi. 10.1016/j.ecoenv.2017.08.021.

[60] Hao J, Ji L, Li C, Hu C, Wu K. Rapid, efficient and economic removal of organic dyes and heavy metals from wastewater by zinc-induced in-situ reduction and precipitation of graphene oxide. J Taiwan Inst Chem Engg. 2017; 164:186-194. doi.10.1016/j.jtice.2018.03.045.

[61] Puri C, Sumana G. Highly effective adsorption of crystal violet dye from contaminated water using graphene oxide intercalated montmorillonite nanocomposite. Appli Clay Sci.2018; 166:102-112. doi. 10.1016/j.clay.2018.09.012.

[62] Magdya YH, Altaher H. Kinetic analysis of the adsorption of dyes from high strength wastewater on cement kiln dust. J Environ Chemi Eng.2018;6:834-841. doi. 10.1016/j.jece.2018.01.009.

[63] Wang Y, Zhu L, Wang X, Zheng W, Hao C,Jiang C, et al. Synthesis of aminated calcium lignosulfonate and its adsorption properties for azo dyes.J Industrial Eng Chem. 2017; 61:321-330.doi: 10.3389/fbioe.2021.691528.

[64] Yang R, Li D, Li A, Yang H. Adsorption properties and mechanisms of palygorskite for removal of various ionic dyes from water. Appl Clay Sci.2018; 151:20-28. doi.10.1016/j.clay.2017.10.016.

[65] Islam MA, Morton DW, Johnson BB, Mainali B, Angove MJ. Manganese oxides and their application to metal ion and contaminant removal from wastewater. J Water Process Eng. 2018; 26:264-280. doi.10.1016/j.jwpe.2018.10.018.

[66] Lei C, Pi M, Jiang C, Cheng B, Yu J. Synthesis of hierarchical porous zinc oxide (ZnO) microspheres with highly efficient adsorption of Congo red. J Colloid Interface Sci. 2017; 490:242-251. doi. 10.1016/j.jcis.2016.11.049.

[67] Lei C, Pi M, Cheng B, Jiang C, Qin J. Fabrication of hierarchical porous ZnO/NiO hollow microspheres for adsorptive removal of Congo red. Appl Surf Sci. 2018; 435:1002-1010. doi.10.1016/j.apsusc.2017.11.201.

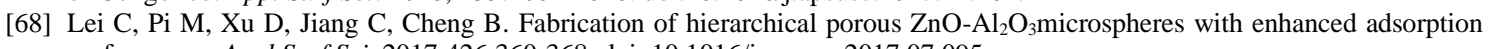
performance. Appl Surf Sci. 2017;426:360-368. doi. 10.1016/j.apsusc.2017.07.095.

[69] Chen H, Motuzas J, Martens W, Diniz da Costa JC. Degradation of Orange II Dye Under Dark Ambient Conditions by MeSrCuO $(\mathrm{Me}=\mathrm{Mg}$ and Ce) Metal Oxides.Sep Purification Tech. 205:293-301. 2018; doi.org/10.1016/j.seppur.2018.05.029. 
[70] Ibrahim MM, El-Molla SA, Ismail SA. Influence of $y$ and ultrasonic irradiations on the physicochemical properties of $\mathrm{CeO}_{2-}$ $\mathrm{Fe}_{2} \mathrm{O}_{3}-\mathrm{Al}_{2} \mathrm{O}_{3}$ for textile dyes removal applications. J Mole Struc. 2018; 1158:234-244.doi.10.1016/j.molstruc.2018.01.034.

[71] Qaiyum MA, Mohanta J, Kumari R, Samal PP, Dey B., Dey S. Alkali treated water chestnut (Trapa natans L.) shells as a promising phytosorbent for malachite green removal from water. IntJ Phytoremediation, 2021;doi. 10.1080/15226514.2021.1977912.

[72] Mohanta J, Kumari R, Qaiyum MA, Dey B, Dey S. Alkali assisted hydrophobic reinforcement of coconut fiber for enhanced removal of cationic dyes: equilibrium, kinetics and thermodynamic insight. Int J Phytoremediation.2021; 23(13):1423-1431 doi.org/10.1080/15226514.2021.1901850.

[73] Mohanta J, Kumari R, Dey B, Dey S. Highly Porous Iron-Zirconium-Zinc Ternary Metal Oxide: Cost Effective Synthesis and Efficient Removal of Malachite Green from Water. J. Chem. Engg. Data. 2021; 66(1):297-307. doi. 10.1021/acs.jced.0c00681

[74] Kumari R, Khan MA, Mahto M, Qaiyum MA, Mohanta J, Dey B, et al. Dewaxed Honeycomb as an Economic and Sustainable Scavenger for Malachite Green from Water. ACS Omega.2020; 5(31):19548-19556. doi.org/10.1021/acsomega.0c02011.

[75] Mohanta J, Dey B, Dey S.Magnetic Cobalt Oxide Nanoparticles: Sucrose-Assisted Self-Sustained Combustion Synthesis, Characterization, and Efficient Removal of Malachite Green from Water. J ChemEngg Data.2020; 65(5):2819-2829. doi.org/10.1021/acs.jced.0c00131.

[76] Mohanta J, Dey B, Dey S.Highly porous iron-zirconium binary oxide for efficient removal of Congo Red from water. Desali Water Treat.2020:189:227-242. doi.org/10.5004/dwt.2020.25570.

[77] Mohanta J, Dey B, Dey S. Sucrose-Triggered, Self-Sustained Combustive Synthesis of Magnetic Nickel Oxide Nanoparticles and Efficient Removal of Malachite Green from Water. ACS Omega. 2020; 5(27):1651016520.doi.org/10.1021/acsomega.0c00999.

[78] Kumari R, Mohanta J, Dey B, Dey S. Eucalyptus leaf powder as an efficient scavenger for Congo red from water: Comprehensive batch and column investigation. Sep SciTech.2019; 55(17):3047-3059. doi.org/10.1080/01496395.2019.1670208.

[79] Kumari R, Dey S. A breakthrough column study for removal of malachite green using coco-peat. Int J Phyto.2019; 21(12):12631271. doi.org/10.1080/15226514.2019.1633252.

[80] Kumari R, Dey S (2019) Synthesis of porous iron - zirconium mixed oxide fabricated ethylene diamine composite for removal of cationic dye. 2019; Desalin. Water Treat., 158, 319-329. https://doi.org/10.5004/dwt.2019.24223

[81] Dey B, Dipty L, Dey S.Efficient Removal of Malachite Green using Saal (Shorea robusta) Flower from Contaminated Water. Int J Green Herb Chem. 2018; 7(2):392-405. doi.org/10.24214/ijghc/gc/7/2/39205.

[82] Kumari R, Dey S. Facile Removal of Congo Red using Mahua (Madhuca longifolia) Seeds, A Low Cost Adsorbent. Int J Green and Herb Chem. 2019; 7(2):237-250. doi.org/10.24214/ijghc/gc/7/2/23750.

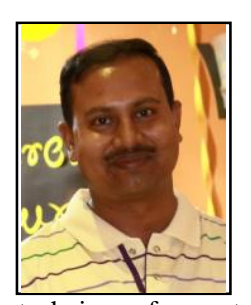

Dr. Soumen Deywas born in Kolkata, India on 16thFebruary 1977. He received his B.Sc., M.Sc. (Chemistry), and B.Ed. degrees from Visva Bharati University, Santiniketan (established by the great Rabindranath Tagore, the first Asian Nobel laureate). Thereafter he moved to Presidency Universityin 2001 and joined as JRF in a project on Arsenic poisoning. He then joined the group of Prof. Sabyasachi Sarkar at I.I.T. Kanpur, India and received a Ph.D. in the year 2009. He joined as an Assistant Professor in the Departmentof Chemistry, S.K.M. University Dumka, India in 2008. In 2011, he moved to the Central University of Jharkhand where he is working as a senior Assistant Professor. So far,he has published 26 research papers in reputed journals and 3 book chapters. He has successfully guided 6 students for their Ph.D. and 35 students for their Master's dissertations. He received major research grant under DST Young Scientist Scheme in 2013. His current research area is to develop environmentally benign techniques for wastewater treatment towards safer health. Various plant-derived materials have been demonstrated as phytosorbents. Magnetic metal oxide nanoparticles have been recently synthesized and used as potentialand sustainablematerials for water treatment. Some representative publications are as follows:

1. Mohanta, J.; Dey, B.; Dey S*. (2020) Magnetic Cobalt Oxide Nanoparticles: Sucrose-Assisted Self-Sustained Combustion Synthesis, Characterization, and Efficient Removal of Malachite Green from Water. J. Chem. Eng. Data, 65: 2819-2829.

2. Kumari,R.; Khan,Md. A.; Mahto,M.; Qaiyum,Md. A. Mohanta, J.;Dey,B.; Dey. S*. (2020) Dewaxed Honeycomb as a Promising Scavenger for Malachite Green from Water, ACS Omega, 5: 19548-19556.

3. Kumari, R., \& Dey, S*. (2019). A breakthrough column study for removal of malachite green using coco-peat. International Journal of Phytoremediation, 21(12), 1263-1271.

Dr. Dey is the twice recipient of 'YOUNG SCIENTIST AWARD' conferred by the Indian Chemical Society in the year 2002 and 2008. He has delivered about 10 invited lectures at various scientific meetings. He is currently a reviewer of many prestigious journals such as Journal of Chemical \& Engineering Data(ACS), Environmental Progress (Wiley), Journal of Chemical\& Environmental Engineering (Elsevier), and International Journal ofPhytoremediation (Taylor and Francis). Dr. Dey is a member of various coveted societies such as the American Chemical Society, Chemical Research Society of India, Indian Council of Chemists, and I.I.T. Kanpur Alumni Association. Apart from academics he also actively takes part in Institutional Management committees; the Academic Council (2015-2020), Board of Studies, Research Advisory Council, and Board of Research. He held the position of 'Coordinator' of the Department of Education (2014-17

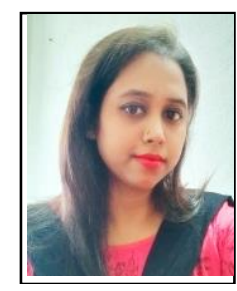

Ms. Priyanka Bhagat was born in Chittaranjan, the rail city in eastern India in 1994. She completed her integrated M.Sc. in 2017 from Central University of Jharkhand and did masters research under Dr. Soumen Dey. Currently she is working as a school teacher in Crescent Public School since January 2021.

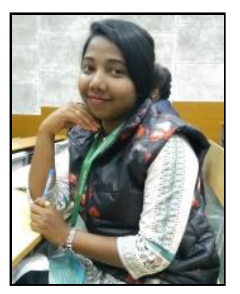

Dr. Jhilirani Mohanta was born in Mayurbhanj district, Odisha, India. She received her M.Sc. from North Orissa University Baripada and M.Phil from Sambalpur University. She then qualified CUCET andadmitted to Ph.D. under Dr. Soumen Dey. She received her Ph.D. in September, 2021. She has published 10 research papers and one book chapter. 


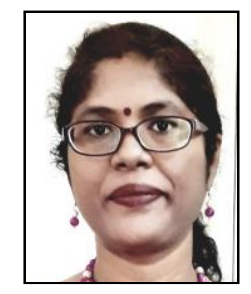

Dr. Banashree Dey was born in steel city Bokaro, Jharkhand, India. She received her M.Sc. from Visva Bharati University Santiniketan, India in 2004 and Ph.D. from Indian Institute of Technology (Indian School of Mines, Dhanbad) in 2014. She has expertise in utilization of fly-ash in various applications. She is currently working as an Assistant Professor and Head in the the Department of Chemistry, The Graduate School College for Women, Jamshedpur, India. She has published over 10 papers in various reputed journals. 